\title{
An Object Relations Model Perspective on the Alternative Model for Personality Disorders (DSM-5)
}

\author{
John F. Clarkin ${ }^{a}$ Eve Caligora, bulia F. Sowislo ${ }^{a}$ \\ a Personality Disorders Institute and Department of Psychiatry, Weill Medical College of Cornell University, \\ New York, NY, USA; ${ }^{b}$ Department of Psychiatry, Vagelos College of Physicians and Surgeons of Columbia University, \\ New York, NY, USA
}

\section{Keywords}

Alternative Model of DSM-5 · Object relations model .

Personality disorders - Treatment of personality disorders

\begin{abstract}
The Alternative Model of DSM-5 combines dimensional ratings of self-functioning, interpersonal functioning, and traits with categorical classification. The object relations model has a long tradition pre-dating the Alternative Model and, in part, has been incorporated into the Alternative Model. The object relations model provides a theoretical background (generally missing in the Alternative Model) that enhances the clinical assessment of personality pathology and its relationship to treatment planning. (2020 The Author(s)

Published by S. Karger AG, Basel
\end{abstract}

\section{Introduction}

The Alternative Model of DSM-5 Section III (AMPD) [1] with its hybrid approach to personality pathology is a work in progress, under theoretical scrutiny, subject to measurement development, and seeking acceptance by clinicians/researchers and the American Psychiatric Association. The hybrid approach combines six specific categories of personality disorder (antisocial, avoidant, borderline, narcissistic, obsessive-compulsive, and schizotypal personality disorder) defined by self- and interpersonal functioning with dimensional ratings and traits. This combination has been described as a clash of traditions in medicine and psychology [2]. It remains to be seen how the combination will enhance assessment and diagnosis of personality pathology.

In contrast, the object relations theory (ORT) model of personality pathology has an extensive history in clinical psychiatry [3] that foreshadowed and predated the AMPD. ORT involves the clinical recognition of observable categories (prototypes) of personality pathology (e.g., borderline and narcissistic personality disorder) while at the same time bringing attention to key domains of functioning that constitute personality pathology, and it can be assessed and measured dimensionally.

Our goal in this article is to compare the central aspects of the AMPD to those of ORT. We focus first on the AMPD with its general criteria for personality disorder and ratings of deficits in self-functioning and interpersonal functioning (criterion A) and pathological traits

$\begin{array}{ll}\text { karger@karger.com } & \text { (c) } 2020 \text { The Author(s) } \\ \text { www.karger.com/psp } & \begin{array}{l}\text { Published by S. Karger AG, Basel } \\ \text { This article is licensed under the Creative Commons Attribution- } \\ \text { Karger }\end{array} \\ \text { JonCommercial 4.0 International License (CC BY-NC) (http:// } \\ \text { www.karger.com/Services/OpenAccessLicense). Usage and distri- } \\ \text { bution for commercial purposes requires written permission. }\end{array}$

John F. Clarkin

Westchester Division, New York Presbyterian Hospital

21 Bloomingdale Road

White Plains, NY 10605 (USA)

jclarkin@med.cornell.edu 
(criterion B). We describe ORT, which has a long history in the psychoanalytic treatment tradition and combines attention to internal mental structure with related behavior. Finally, we compare the two models on key aspects of interest, including the definition of personality disorder, the ease and methods of assessment, and the model's relationship to treatment planning.

\section{Description of and Rationale for the Alternative Model}

The categorical diagnosis of personality disorders introduced in the DSM-III [4] and utilized in its subsequent versions was an impetus to empirical work on personality pathology but revealed a number of serious flaws in its application. These difficulties are well documented, including the heterogeneity within the individual diagnoses and the extensive co-morbidity among the disorders. Thus, the scene was set for major adjustments in the DSM-5, which resulted in conserving the categorical approach in the DSM-5 but including an Alternative Model in Section III, Emerging Measures and Models.

\section{Dimensional Approach versus Categorical Approach}

A primary intent of the DSM-5 initiative was to improve on the DSM-IV by an emphasis on dimensional measurement to more adequately capture the complexity and severity of pathology. The AMPD has taken the bold and controversial step of combining the categorical approach, describing six specific personality disorders, with dimensional measurement of self-functioning, interpersonal functioning, and traits. This has been called a clash of two traditions, the categorical tradition coming from medicine, and the dimensional, trait approach coming from academic psychology [2].

\section{General Criteria for the Diagnosis of Personality Disorder}

The AMPD has a number of criteria that capture the definition of personality disorder. Personality disorder involves the presence of significant impairments in selffunctioning and interpersonal functioning. In addition, one or more pathological traits are present. The personality dysfunction described in this way is both inflexible and pervasive across a range of personal and social situations, and the dysfunction is relatively stable across time since adolescence or early adulthood.

Criterion A and Background Rationale. Criterion A defines the domains of self-functioning and interpersonal functioning that are seen as central to personality pathology. Self-functioning is specified as identity, self-direction (short- and long-term goals, standards of behavior, self-reflection), sense of self as a unique individual with clear boundaries, positive self-esteem, and accuracy of self-appraisal. Interpersonal functioning is defined by the capacity for empathy for and intimacy with others. A review of empirical data and theoretical writings showing the importance of self-functioning and interpersonal functioning to the overall severity of personality pathology was influential in the architecture of the AMPD [5]. This review noted that Kernberg's ORT was one of the first to articulate a model of personality types arrayed along a continuum of severity. This review led the way to the dimensional rating of self-functioning and interpersonal functioning, the Level of Personality Functioning Scale (LPFS).

Criterion B and Background Rationale. Criterion B is composed of five high-order traits: negative affect, detachment, antagonism, disinhibition, and psychoticism. These five higher-order traits have a number of related facets, not all of which are clearly indicated by the higherorder trait name. Negative affectivity, for example, includes facets of emotional lability, anxiousness, separation insecurity, submissiveness, hostility, and perseveration. The advantage of the multiple facets is coverage of numerous trait domains. A disadvantage is the lack of a theory that provides an indication of the overall importance of the multiple domains and facets to the functioning of the individual patient in his/her unique environment. Trait theory has a long tradition in clinical psychology for understanding and measuring personality functioning $[6,7]$. A "trait" can be defined as a variable underlying a relatively stable disposition by the individual toward particular behavior patterns [7]. For example, the trait of aggression indicates that the individual is more likely than others who are lower on the trait dimension to exhibit behavior that is aggressive under stressful situations. The different traits are then used together to characterize an individual's functioning. There are a number of trait models, and the one adopted for the Alternative Model is conceptualized as a variant of the Big Five model. There are, however, a number of limitations in the trait approach in general, and in the use of a trait approach in the clinical assessment of patients [8]. Treatment is not focused on traits in the abstract, but rather on the triggers and contexts in which the disposition is turned into disruptive behavior. This requires that the clinical evaluation focus on the perceptions of the patient and the contexts in which the trait or disposition is activated. 


\section{Description of the ORT Model of Personality Pathology}

The ORT model $[9,10]$ has its origins in the clinical understanding of patients engaged in intensive psychodynamic treatment and predates the theoretical focus on self-functioning and other functioning in the AMPD. The ORT of personality functioning and pathology is anchored in the construct of identity. Identity is the psychological structure seen to organize self- and interpersonal functioning, and pathology of identity formation seen as the defining feature of the personality disorders [3]. Normal identity formation, or identity consolidation, corresponds to a core sense of self that is stable, coherent, realistic, and continuous across time, a corresponding stable and rich experience of significant others, and an affective experience that is complex and well modulated. A coherent and integrated conception of self and others contributes to relationships that involve empathy and mutual dependence, as well as the ability to "mentalize," that is, to understand self and others in terms of intentions, motivations, and emotions.

In contrast, personality disorders at the level of borderline organization (e.g., borderline personality disorder) are characterized by pathology of identity formation, reflected in the absence of a fully elaborated, stable, and coherent core sense of self. In this setting, the experience of self and also of others is unstable, discontinuous, distorted, and poorly contextualized, and affects are poorly integrated and poorly modulated. Failure of identity consolidation is also associated with difficulty identifying and sustaining longer-term goals as well as with impaired capacity for empathy.

From a dynamic perspective, failure of identity formation reflects the impact of splitting-based or dissociative defenses, which interfere with normal integrative processes. Representations of self and others associated with positive affective experience are dissociated from those associated with negative affective experience. The resulting affectively charged, polarized internal representations fail to coalesce into an overarching sense of self and others. This is seen as accounting for the unstable and distorted sense of self and others that characterizes the personality disorders. In contrast, in normal identity formation, individual representations of self and others coalesce to form a coherent, integrated supraordinate sense of self, associated with both positive and negative affective experience and corresponding experience of significant others.

Classification of personality pathology within the framework of ORT focuses on core domains viewed as central to healthy personality functioning and disrupted in the personality disorders. Similar to the AMPD, the model emphasizes (1) identity formation (sense of self, sense of others, capacity to pursue longer-term personal goals) and (2) object relations (working models of relationships organizing interpersonal functioning). The ORT model is distinguished from the AMPD in that it also emphasizes the nature of (3) defensive operations, (4) the quality and management of aggression, (5) moral functioning and internalized values, and (6) reality testing as core determinants of personality functioning and the severity of personality pathology [9] (in the AMPD these features could be included as "trait specifiers"). Assessment of the nature and level of organization of functioning in these six domains provides both a dimensional profile of personality functioning and a determination of the individual's personality organization. Much as is seen in the LPFS, determination of personality organization, or the level of personality organization, can lead to classification of personality disorders on the basis of prototypes representing the severity of personality pathology falling across a continuous spectrum of pathology ranging from healthy personality functioning through severe pathology and linking its diagnostic classification to prognosis and treatment planning [10]. In the ORT model, severity of personality pathology is accompanied not only by deterioration of self- and interpersonal functioning as is noted in the AMPD, but also by deteriorating moral functioning (antisocial traits), increasing centrality of aggression (which may be self-directed as well as other-directed) in psychological functioning, and vulnerability of reality testing in the setting of extreme activation or conflict.

Because the ORT model has traditionally been focused on self (i.e., identity, defensive functioning, moral functioning, moderation of aggression) and functioning with others (i.e., quality of object relations) it has a close affinity with the AMPD. However, a major advantage of the ORT model is its theoretical and conceptual focus and clarity in contrast to the descriptive nature of the AMPD model. Clinical experience has confirmed that the five domains of functioning in ORT are central determinants of the level of organization and functioning of the individual with a close relationship to treatment focus and prognosis.

\section{Comparison of the ORT Model with the AMPD}

Aided by a background of information on both models of personality pathology and functioning, one can compare the two models on central aspects of interest. 


\section{Definition of Personality Disorder}

A major contribution of the AMPD is a clear conception of the essence of personality pathology, which was missing in the DSM-III and its successors. The focus on self-functioning and functioning with others in interpersonal relations has theoretical and empirical support. The border between some difficulties and a personality disorder is clarified by the LPFS rating, which anchors the pathology with defined levels of severity.

The definition of personality disorder in ORT begins with a conceptualization of personality and normal personality functioning. Personality is the dynamic integration of behavior patterns derived from temperament, cognitive capacities, character and its subjective correlate of identity, and internalized value systems. A full view of personality must include the internal world of the individual and observable behavior patterns. Clinical assessment leads to a level of severity of difficulties in the organization of the personality, i.e., normal, neurotic, and high-, mid-, or low-level borderline organization. Consistent with the AMPD LPFS, moderate impairment is required for a personality disorder diagnosis. Thus, neurotic organization is considered subthreshold for the diagnosis, and a borderline level of organization at various levels of severity characterizes the personality disorders proper.

\section{Domains of Functioning Relevant to the Two Models}

There is, in fact, a considerable overlap between the domains of functioning as identified in AMPD criterion $\mathrm{A}$ and the domains of functioning privileged in the ORT model. Self-functioning in the AMPD is composed of identity and self-direction. These domains are captured extensively in the ORT model by Identity. The Interpersonal Functioning domain of the AMPD is composed of empathy and intimacy, both highlighted in the ORT domain of Object Relations. The five traits identified in the AMPD are evaluated in ORT by the domains of Aggression (negative affect), Object Relations (detachment, antagonism, disinhibition), and Reality Testing (psychoticism).

There are, however, several domains of functioning prominent in the ORT model that are not prominent in the alternative model. Defenses, spanning from normal defensive maneuvers and neurotic ones (rigidity, repression) to more extreme measures (e.g., splitting) are assessed in ORT. Furthermore, moral functioning, which can be variable in most personality disorders but is most evident in its absence in antisocial personality disorder, is an important domain of functioning in ORT. The ORT model posits that degrees of moral functioning deficits are involved not only in antisocial personality disorder but potentially also in all severe personality disorders, in particular among patients presenting with borderline, narcissistic, and paranoid personality disorders and malignant narcissism. In these disorders, the presence and extent of deficits in moral functioning serve as a robust marker of severity of personality pathology.

The two models arrived at their respective domains by different routes. The five domains of interest in the ORT model were derived from clinical experience and theoretical reflection on those domains of human functioning that are consistently related to personality pathology [3]. This theoretical formulation has been called upon to inform the selection of self-functioning and interpersonal functioning in AMPD criterion A.

In contrast, personality researchers emphasize that the higher-order traits included in AMPD criterion B are not based on mere theory but rather on a sound empirical approach. What is the foundation for this claim? The generation of traits is based upon a lexical examination of nouns and adjectives that describe human behavior. These items are placed in a self-report instrument and subjected to factor analysis to yield traits. This process is empirical in the sense that factor analysis is applied to the data. However, the data are typically self-report information from individuals, subject to the limitations of accuracy on the part of the respondent. Factor analysis is based on correlations between responses across the sample, and it not descriptive of any one individual.

\section{Clinical Assessment}

The time-honored assessment procedure between prospective patient and therapist is the clinical interview. The major goal of the clinical assessment is to provide a clear focus (to both the patient and the therapist) for the therapeutic intervention. Through the process of evaluation, patient and therapist come to a clearer and shared conceptualization of the targets of intervention and the patient's motivation for change. The clinical interview has the advantage of direct contact between patient and potential therapist and provides direct evidence of the quality of the patient's relations with others. An important practical issue is how the two different models would guide the clinical assessment interview.

There is little information on how the AMPD would guide the initial clinical interview in terms of organization and sequence. The content of the AMPD would dictate that the clinical interview pursues information concerning self-functioning (identity and self-direction) and 
important interactions with others in the individual's current environment (criterion A). There are several semi-structured interviews (detailed later in this article) that can guide the clinician in this process. This information would also inform the assessor's ratings of the traits in criterion B.

The structure and focus of the clinical assessment interview according to ORT is informed by the structural interview [3]. The sequence of this clinical but clearly defined interview proceeds from chief complaint and motivation for change, to prominent current symptoms, to the extent and quality of interpersonal relations. The yield of the interview is information that can be used to make a diagnosis of the type and severity of personality disorder. In cases of personality pathology where there are questions of possible thought disorder, deficits in cognitive functioning, etc., a more extensive assessment battery could be utilized.

\section{Ancillary Assessment Procedures}

Criterion A of the AMPD (i.e., severity) can be operationalized by ratings on the LPFS, either by an expert clinician, the participant her-/himself, or an informant [for an overview, see 11]. These ratings can be made either on a global level (i.e., single 5-point scale) or on a more differentiated level (i.e., separate ratings of the 4 domains, the 12 subdomains, or the 60 prototypical descriptions). Information relevant to the clinician ratings can be collected using one of several structured clinical interviews, such as the Structured Clinical Interview for the Level of Personality Functioning Scale [12] or the Semi-Structured Interview for Personality Functioning DSM-5 [13]. In addition to that, more recently, self-report measures corresponding to the LPFS have been developed. These include the Level of Personality Functioning Scale-Self Report [14] and its brief form [15], the DSM-5 Levels of Personality Functioning Questionnaire [16], and the Self and Interpersonal Functioning Scale [17].

Criterion B of the AMPD (i.e., maladaptive traits) can as well be operationalized by expert clinician report, selfreport, or informant report. The most common way to measure criterion B is the Personality Inventory for DSM5 [18], a 220 -item self-report questionnaire which assesses the 25 facet traits and the 5 higher-order traits. Additionally, a short form with 100 items [19], a brief form with 25 items [20], and an informant report form [21] are available. Expert clinician ratings can be done using the Personality Trait Rating Form [22], which includes 25 items measuring the facet traits, whereby the necessary information for those ratings can be gained using the Structured Clinical Interview for Personality Traits [23]. These developing instruments for criteria $A$ and $B$ are useful for research, but their role in clinical practice will probably be minor, as most clinicians do not use questionnaires in routine practice and prefer the clinical interview.

The clinical assessment of patient symptoms and personality organization in ORT can be accomplished using the structural interview [3], and its semi-structured interview format as described in the Structured Interview for Personality Organization (STIPO) $[24,25]$ and the shorter revision, the STIPO-R [24]. The STIPO-R is not only useful for research, but it can also be a guide for the clinician performing an initial patient evaluation.

STIPO ratings of severity are consistent with diagnostic measures of pathology. The STIPO domains discriminate between clinical and nonclinical subjects. There is a significant correlation between personality organization on the STIPO and the number of SCID-II diagnoses. Patients with DSM personality disorder were found to be on a lower level of personality organization in all domains than were patients without personality disorder. Based on the domain ratings of the STIPO, a prototypical profile of borderline personality organization (BPO) was developed and tested in its ability to discriminate between $\mathrm{BPO}$ and non-BPO.

STIPO domain ratings are useful in assessing clinical engagement and change. For example, STIPO domains identify treatment dropout among dual-diagnosis patients more effectively than do personality disorder diagnoses. In a randomized clinical trial comparing transference-focused psychotherapy to treatment in the community by expert therapists, the STIPO detected change in personality organization in both groups, with superior change in the transference-focused psychotherapy group.

\section{Description versus Hypothesized Connections}

Traits (criterion B) are descriptions of action tendencies as reported by subjects on self-report questionnaires. Criterion $\mathrm{A}$ is a description of aspects of self- and interpersonal functioning. In contrast, ORT is a clinically based theoretical model that posits cause and effect between internalized object relations empowered by strong affects as they impact on the nature and quality of interactions between self and others. This type of model provides a road map for treatment intervention. 
Table 1. Severity of personality pathology: implications for assessment and treatment parameters [10]

\begin{tabular}{|c|c|c|c|c|}
\hline & Neurotic organization & $\begin{array}{l}\text { High borderline personality } \\
\text { organization }\end{array}$ & $\begin{array}{l}\text { Mid borderline personality } \\
\text { organization }\end{array}$ & $\begin{array}{l}\text { Low borderline personality } \\
\text { organization }\end{array}$ \\
\hline $\begin{array}{l}\text { Level of Personality } \\
\text { Functioning Scale } \\
\text { (LPFS) }\end{array}$ & Level 1 & Level 2 & Level 3 & Level 4 \\
\hline $\begin{array}{l}\text { Typical categorical } \\
\text { diagnosis }\end{array}$ & $\begin{array}{l}\text { Obsessive compulsive PD; } \\
\text { depressive PD; hysterical PD }\end{array}$ & $\begin{array}{l}\text { Dependent PD; histrionic } \\
\text { PD; avoidant PD; narcissistic } \\
\text { PD }\end{array}$ & $\begin{array}{l}\text { Narcissistic PD; } \\
\text { borderline PD; paranoid PD; } \\
\text { schizoid PD }\end{array}$ & $\begin{array}{l}\text { Narcissistic, borderline, } \\
\text { and paranoid PDs with } \\
\text { antisocial features; } \\
\text { antisocial PD }\end{array}$ \\
\hline $\begin{array}{l}\text { Nature of self-other } \\
\text { functioning }\end{array}$ & $\begin{array}{l}\text { Integrated, realistic, and } \\
\text { continuous experience of self } \\
\text { in relation to others; } \\
\text { relationships characterized by } \\
\text { mutuality }\end{array}$ & $\begin{array}{l}\text { Somewhat superficial and/or } \\
\text { polarized experience of self } \\
\text { in relation to others; some } \\
\text { capacity for dependency but } \\
\text { with conflict }\end{array}$ & $\begin{array}{l}\text { Superficial, extreme, } \\
\text { polarized, and unstable sense } \\
\text { of self in relation to others } \\
\text { with gross distortion; need- } \\
\text { fulfilling relationships }\end{array}$ & $\begin{array}{l}\text { Caricature-like, extreme, } \\
\text { highly polarized, and } \\
\text { chaotic sense of self in } \\
\text { relation to others with } \\
\text { gross distortion; } \\
\text { exploitative relationships }\end{array}$ \\
\hline Prognosis & Excellent & Good & Fair & Very guarded \\
\hline $\begin{array}{l}\text { Structuring of the } \\
\text { treatment }\end{array}$ & $\begin{array}{l}\text { Less need for structured } \\
\text { contract }\end{array}$ & $\begin{array}{l}\text { Explicitly agreed-upon } \\
\text { treatment contract promotes } \\
\text { productive clinical process }\end{array}$ & $\begin{array}{l}\text { Carefully constructed } \\
\text { treatment contract is essential }\end{array}$ & $\begin{array}{l}\text { Contracting must be } \\
\text { extensive; focus on } \\
\text { secondary gain and safety } \\
\text { of patient and therapist }\end{array}$ \\
\hline Treatment process & Little to no risk of acting out & $\begin{array}{l}\text { Risk of low-level acting out } \\
\text { (e.g., poor attendance) }\end{array}$ & $\begin{array}{l}\text { Risk of dangerous acting out } \\
\text { (e.g., suicide gestures or } \\
\text { attempts, substance misuse) }\end{array}$ & $\begin{array}{l}\text { Potentially lethal acting out } \\
\text { (e.g., threats of violence } \\
\text { to therapist, lethal suicide } \\
\text { attempts) }\end{array}$ \\
\hline Alliance & $\begin{array}{l}\text { Clarity about seeking help } \\
\text { from expert; open to alliance }\end{array}$ & $\begin{array}{l}\text { Ambivalence about seeking } \\
\text { help and depending on } \\
\text { expert interference with } \\
\text { initial alliance; early alliance } \\
\text { unstable or superficial }\end{array}$ & $\begin{array}{l}\text { Suspicion, with fear of critical } \\
\text { attack or exploitation by } \\
\text { therapist interferes with } \\
\text { alliance; alliance built during } \\
\text { course of treatment }\end{array}$ & $\begin{array}{l}\text { Relatively fixed view of } \\
\text { therapist as corrupt, } \\
\text { arrogant, and exploitative } \\
\text { limits capacity to form an } \\
\text { alliance }\end{array}$ \\
\hline
\end{tabular}

$\mathrm{PD}$, personality disorder.

\section{Contribution of the Assessment Process to Treatment Planning}

An essential approach to the evaluation of a diagnostic system is to review its clinical utility: how well does it meet the needs of clinicians evaluating and treating patients. Aspects of clinical utility include user acceptability and utility, professional communication, interrater reliability, subtlety of diagnosis, and clinical decision-making [26]. The evidence for the clinical utility of the AMPD is just beginning to be accumulated, with evidence that clinicians prefer the emphasis on dimensional assessment [27].

A major consideration is the relevance of the assessment process to the clinician's articulation of a treatment plan, and the communication between clinician and patient concerning the need, focus, and process of treatment intervention. The relationship between the AMPD and treatment planning is only implicit and not articulated in the diagnostic manual. This gap in the diagnostic manual is understandable and fitting, as it is not the role of the AMPD to make choices between competing treatment orientations that must be judged empirically aside from the diagnostic process.

A major advantage of the ORT model is the direct linkages it makes between a theoretical focus on key domains of functioning, assessment techniques and methods, and treatment planning [24]. Table 1 describes the relationship between levels of personality organization, as revealed in the structural interview or in a clinical interview guided by the STIPO-R, and key aspects of the treatment process. The severity of the level of personality organiza- 
tion disturbance is directly related to the structure and focus of the therapeutic intervention.

\section{Conclusions}

The inclusion of the AMPD in the DSM-5 has provided a positive stimulus to refining our conceptions of personality pathology and its assessment. A primary concern in the evaluation of the AMPD is its suitability to be included as the official diagnostic system. Does it meet the clinical and administrative requirements for a diagnostic system [26]? At this point, it is our view that its central focus on self-functioning and functioning with others is a positive advance over the current system. In addition, the emphasis on dimensional ratings of domains of functioning (i.e., severity) is essential for treatment planning.

An important perspective, however, is an evaluation of the AMPD as an expression of how the field is advancing in the understanding of personality pathology. The debates over the AMPD go far beyond its value in diagnosing patients (the reporting of the diagnosis to insurance companies in the USA is done with the ICD-10) and at- tracts intense debate on the very nature and classification of personality pathology. It is this articulation of the growing view of personality pathology that is so important for the field. With the infusion of developing research, it is possible that the differences between two traditions in the AMPD can be transformed into a more integrated view.

\section{Conflict of Interest Statement}

The authors have no conflicts of interest to declare.

\section{Funding Sources}

This work was supported by a research grant from the Swiss National Science Foundation to J.F.S.

\section{Author Contributions}

J.F.C. drafted the manuscript. E.C. and J.F.S. critically revised the manuscript. All authors reviewed the final manuscript.

\section{References}

1 American Psychiatric Association. Diagnostic and statistical manual of mental disorders. 5th ed. Arlington (VA): American Psychiatric Association; 2013.

2 Kendler KS. Classification of psychopathology: conceptual and historical background. World Psychiatry. 2018 Oct;17(3):241-2.

3 Kernberg OF. Severe personality disorders: psychotherapeutic strategies. New Haven (CT): Yale University Press; 1984

4 American Psychiatric Association. Diagnostic and statistical manual of mental disorders. 3rd ed. Arlington (VA): American Psychiatric Association; 1980.

5 Bender DS, Morey LC, Skodol AE. Toward a model for assessing level of personality functioning in DSM-5, part I: a review of theory and methods. J Pers Assess. 2011 Jul;93(4):332-46.

6 Kotov R, Krueger RF, Watson D, Achenbach TM, Althoff RR, Bagby RM, et al. The Hierarchical Taxonomy of Psychopathology (HiTOP): a dimensional alternative to traditional nosologies. J Abnorm Psychol. 2017 May;126(4):454-77.

7 Markon KE, Jonas KG. The role of traits in describing, assessing, and understanding personality pathology. In: Huprich SK, editor. Personality disorders: toward theoretical and empirical integration in diagnosis and assessment. Washington (D.C): American Psychological Association; 2015. pp. 63-84.
8 Meehan KB, Clarkin JF. A critical evaluation of moving toward a trait system for personality disorder assessment. In: Huprich SK, editor. Personality disorders: toward theoretical and empirical integration in diagnosis and assessment. Washington (D.C): American Psychological Association; 2015. pp. 85-106.

9 Kernberg OF, Caligor E. A psychodynamic theory of personality disorders. In: Lenzenweger MF, Clarkin JF, editors. Major theories of personality disorder. 2nd ed. New York (NY): Guilford Press; 2005. pp. 114-56.

10 Caligor E, Kernberg OF, Clarkin JF, Yeomans FE. Psychodynamic therapy for personality pathology: treating self and interpersonal functioning. Washington (D.C.): American Psychiatric Association Publishing; 2018.

11 Zimmermann J, Kerber A, Rek K, Hopwood CJ, Krueger RF. A brief but comprehensive review of research on the Alternative DSM-5 Model for Personality Disorders. Curr Psychiatry Rep. 2019 Aug;21(9):92.

12 Bender DS, Skodol AE, First MB, Oldham JM. Module I: Structured Clinical Interview for the Level of Personality Functioning Scale. In: First MB, Skodol AE, Bender DS, Oldham JM, editors. Structured Clinical Interview for the DSM-5 Alternative Model for Personality Disorders (SCID-AMPD). Arlington (VA): American Psychiatric Association Publishing; 2018.
13 Hutsebaut J, Kamphuis JH, Feenstra DJ, Weekers LC, De Saeger H. Assessing DSM5-oriented level of personality functioning: development and psychometric evaluation of the Semi-Structured Interview for Personality Functioning DSM-5 (STiP-5.1). Personal Disord. 2017 Jan;8(1):94-101.

14 Morey LC. Development and initial evaluation of a self-report form of the DSM-5 Level of Personality Functioning Scale. Psychol Assess. 2017 Oct;29(10):1302-8.

15 Hutsebaut J, Feenstra DJ, Kamphuis JH. Development and preliminary psychometric evaluation of a brief self-report questionnaire for the assessment of the DSM-5 Level of Personality Functioning Scale: the LPFS Brief Form (LPFS-BF). Personal Disord. 2016 Apr; 7(2):192-7.

16 Huprich SK, Nelson SM, Meehan KB, Siefert CJ, Haggerty G, Sexton J, et al. Introduction of the DSM-5 Levels of Personality Functioning Questionnaire. Personal Disord. 2018 Nov;9(6):553-63.

17 Gamache D, Savard C, Leclerc P, Côté A. Introducing a short self-report for the assessment of DSM-5 level of personality functioning for personality disorders: the Self and Interpersonal Functioning Scale. Personal Disord. 2019 Sep;10(5):438-47. 
18 Krueger RF, Derringer J, Markon KE, Watson D, Skodol AE. Initial construction of a maladaptive personality trait model and inventory for DSM-5. Psychol Med. 2012 Sep;42(9): 1879-90.

19 Thimm JC, Jordan S, Bach B. The Personality Inventory for DSM-5 Short Form (PID-5-SF): psychometric properties and association with Big Five traits and pathological beliefs in a Norwegian population. BMC Psychol. 2016 Dec;4(1):61.

20 Bach B, Maples-Keller JL, Bo S, Simonsen E. The alternative DSM-5 personality disorder traits criterion: a comparative examination of three self-report forms in a Danish population. Personal Disord. 2016 Apr;7(2):124-35.

21 Markon KE, Quilty LC, Bagby RM, Krueger RF. The development and psychometric properties of an informant-report form of the Personality Inventory for DSM-5 (PID-5). Assessment. 2013 Jun;20(3):370-83.
22 Few LR, Miller JD, Rothbaum AO, Meller S, Maples J, Terry DP, et al. Examination of the Section III DSM-5 diagnostic system for personality disorders in an outpatient clinical sample. J Abnorm Psychol. 2013 Nov;122(4): 1057-69.

23 Skodol AE, First MB, Bender DS, Oldham JM. Module II: Structured Clinical Interview for Personality Traits. In: First MB, Skodol AE, Bender DS, Oldham JM, editors. Structured Clinical Interview for the DSM-5 Alternative Model for Personality Disorders (SCID-AMPD). Arlington (VA): American Psychiatric Association Publishing; 2018.

24 Clarkin JF, Caligor E, Stern B, Kernberg OF. The Structured Interview of Personality Organization - Revised (STIPO-R). 2016. Available from: https://www.borderlinedisorders. $\mathrm{com} /$ structured-interview-of-personality-organization.php.
25 Hörz-Sagstetter S, Caligor E, Preti E, Stern BL, De Panfilis C, Clarkin JF. Clinician-guided assessment of personality using the Structural Interview and the Structured Interview of Personality Organization (STIPO). J Pers Assess. 2018 Jan-Feb;100(1):30-42.

26 Verheul R. Clinical utility of dimensional models for personality pathology. In: Widiger TA, Simonsen E, Sirovatka PJ, Regier DA, editors. Dimensional models of personality disorders: refining the research agenda for DSMV. Washington (DC): American Psychiatric Association; 2006. pp. 203-18.

27 Bornstein RF, Natoli AP. Clinical utility of categorical and dimensional perspectives on personality pathology: a meta-analytic review. Personal Disord. 2019 Nov;10(6):47990. 